\title{
SISTEM PAKAR DIAGNOSIS PENYAKIT JERAWAT DI WAJAH DENGAN METODE CERTAINTY FACTOR
}

\author{
Ketut Arlin Aryani ${ }^{1}$, Dewa Gede Hendra Divayana ${ }^{2}$, I Made Agus Wirawan ${ }^{3}$ \\ 1,2,3 Jurusan Pendidikan Teknik Informatika/Universitas Pendidikan Ganesha \\ Singaraja,Bali \\ e-mail : arlinaryani28@gmail.com¹, hendra.divayana@undiksha.ac.id², \\ imade.aguswirawan@undiksha.ac.id ${ }^{3}$
}

\begin{abstract}
Abstrak
Penelitian ini bertujuan: (1) Menghasilkan sebuah sistem pakar diagnosis penyakit jerawat di wajah dengan metode certainty factor. (2) Mengetahui tingkat akurasi sistem pakar diagnosis penyakit jerawat di wajah dengan metode certainty factor. Penelitian ini diharapkan mampu mengatasi permasalahan jerawat yang dialami oleh masyarakat sehingga dapat menjadi sebagai langkah pencegahan dini untuk mencegah penyakit jerawat menjadi semakin meradang. Selain itu, sistem ini dapat membantu dokter untuk mendiagnosa pasien dan dapat menyimpan hasil rekam medis pasien sebagai bahan pertimbangan dalam pemberian treatment selanjutnya. Jenis penelitian ini adalah penelitian dan pengembangan (Research and Development) dengan model penelitian Rapid Application Development (RAD). Untuk proses pengujian, dilakukan tiga (3) tahap proses pengujian yaitu: (1) uji whitebox, (2) uji blackbox, dan (3) uji akurasi sistem. Hasil dari uji akurasi sistem diperoleh akurasi penuh sebesar $85 \%$, akurasi sebagian sebesar $15 \%$ dan error sebesar $0 \%$.
\end{abstract}

Kata kunci: Sistem Pakar, Jerawat, Certainty Factor

\begin{abstract}
The purpose of this research are : (1) Resulting a diagnosis expert system of acnes on face using Certainty Factor method. (2) Knowing the level of accuracy of the expert system of acne disease diagnosis on the face with certainty factor method. This research is expected to be able to overcome the problems of acne experienced by the community so it can be as a preventive measure early to prevent acne disease becomes increasingly inflamed. In addition, this system can help doctors to diagnose patients and can save the results of medical records of patients for consideration in the provision of further treatment. This research type is research and development with research model of Rapid Application Development (RAD). For the testing process, three (3) test process stages are: (1) whitebox test, (2) blackbox test, and (3) system accuracy test. The result of system accuracy test is $85 \%$ for full accuracy, $15 \%$ for half accuracy and $0 \%$ for error.
\end{abstract}

Keywords : Expert System, Acne, Certainty Factor

\section{PENDAHULUAN}

Kabupaten Buleleng terletak di belahan utara pulau Bali memanjang dari barat ke timur dan mempunyai pantai sepanjang $144 \mathrm{~km}$, secara geografis terletak pada posisi $8^{\circ} 03^{\prime} 40^{\prime \prime}-8^{\circ} 23^{\prime} 00^{\prime \prime}$ lintang selatan dan $114^{\circ} 25^{\prime} 55^{\prime \prime}-115^{\circ} 27^{\prime} 28^{\prime \prime}$ bujur timur. Kabupaten Buleleng memiliki iklim laut tropis yang dipengaruhi oleh angin musim dan terdapat musim kemarau dan penghujan. Curah hujan terendah di di daerah pantai dan tertinggi di daerah pegunungan. Suhu udara rata-rata tinggi, karena matahari selalu berada di garis vertikal. Umumnya suhu udara di Buleleng antara $26-30^{\circ} \mathrm{C}$. Iklim tropis tersebut membawa dampak positif dan dampak negatif bagi masyarakat. Umumnya iklim tropis membawa berkah bagi kesuburan tanaman karena terdapat 2 musim yaitu 
musim hujan dan musim kemarau sedangkan dampak negatif dari adanya iklim tropis adalah timbulnya masalah kulit yang terjadi di masyarakat.

Penyakit kulit yang timbul akibat pengaruh iklim tropis antara lain panu (menyerang daerah lipatan kulit), kudis (umumnya menyerang daerah yang tertutup misalnya punggung dan badan), kurap (menyerang daerah yang kasar dan bersisik misalnya kaki dan tangan) dan jerawat (menyerang daerah muka dan badan). Dari data statistik menunjukkan bahwa hampir $85 \%$ orang berusia $12-25$ tahun pernah mempunyai masalah dengan jerawat yang berdampak pada citra diri seseorang [1]. Menurut Stuart \& Sundeen (1991) dalam [2] citra diri atau gambaran diri adalah sikap seseorang terhadap tubuhnya secara sadar dan tidak sadar. Munculnya jerawat dibagian wajah pada remaja dapat menyebabkan gangguan psikologis dan pengembangan kepribadiannya dalam tahap tumbuh kembang seperti kurangnya percaya diri, malu, sampai dengan harga diri rendah.

Penyebab terjadinya jerawat yaitu terjadinya penyumbatan pada saluran kelenjar minyak, tertutupnya saluran keluar kelenjar sebasea olah massa eksternal, baik dari kosmetik, bahan kimia, debu dan polusi serta saluran keluar kelenjar sebasea menyempit (hiperkeratosis) akibat radiasi sinar ultraviolet, sinar matahari, atau sinar radio aktif [3]. Jenis-jenis jerawat antara lain yaitu jerawat blackhead, whitehead, papula, pustula, nodula conglobate/kista. Berdasarkan dari jenis jerawat tersebut memiliki tingkat kelompoknya masingmasing, yaitu dari tingkat ringan (mild), sedang (moderate) dan berat (severe). Sedikitnya tingkat kesadaran bagi penderita jerawat disebabkan karena kurangnya pengetahuan tentang penyakit jerawat dan juga keterbatasan waktu maupun biaya untuk konsultasi ke dokter spesialis. Oleh sebab itu, perlu adanya sebuah media informasi kepada penderita jerawat yang bertujuan untuk memberikan pemahaman mengenai jenis jerawat, tingkat kelompok jerawat, saran mengatasi penyakit jerawat berdasarkan tingkatannya, dan informasi umum mengenai penyakit jerawat. Keterbatasan dokter/pakar masing-masing bidang menyebabkan masyarakat kesulitan dalam melakukan konsultasi kesehatan. Melakukan face to face dengan dokter spesialis memakan banyak waktu karena harus mengantri akibat minimnya ketersediaan dokter spesialis dan mengeluarkan biaya yang tidak sedikit. Oleh karena itu, semakin berkembangnya teknologi yang sangat pesat, hasil dari pemikiran dan pelatihan pakar dapat diadopsi dengan menggunakan teknologi Kecerdasan Buatan (Artificial Intelligence), khususnya sistem pakar.

Berdasarkan paparan tersebut,
penulis menuangkan ide untuk mengembangkan Sistem Pakar Diagnosis Penyakit Jerawat di Wajah dengan Metode Certainty Factor. Sistem pakar tersebut dibangun dengan menggunakan mesin inferensi forward chaining dan backward chaining serta metode yang digunakan dalam penelitian ini adalah certainty factor. Metode ini dapat membantu dalam menyatakan nilai kepastian sebuah fakta atau hipotesis berdasarkan bukti atau penilaian pakar. Pakar yang digunakan dalam pembuatan sistem ini adalah dr. Anak Agung Ngurah Wandy Mastika. Sistem ini hanya membatasi 6 jenis penyakit jerawat vulgaris (acne vulgaris) dan 3 tingkat keparahan jerawat (grading sistem by James and Tisserand) [4]. Sistem ini nantinya akan mengeluarkan output berupa informasi mengenai tingkatan jerawat berdasarkan jenis penyakit yang dialami berikut dengan persentase jenis jerawatnya serta solusi penanganan masalah jerawat berdasarkan tingkatan jerawatnya.

\section{KAJIAN TEORI}

A. Jerawat

Jerawat adalah penyakit yang sangat kompleks dengan unsur patogenesis melibatkan cacat pada epidermis keratinisasi, sekresi androgen, fungsi sebaceous, pertumbuhan bakteri, peradangan, dan imunitas. Jerawat umumnya terjadi pada masa remaja dan dapat sembuh sendiri. Defenisi lain jerawat disebut juga acne vulgaris atau common acne dimana lesi paling sering dijumpai 
pada wajah, dada dan punggung. Kelenjar yang meradang dapat membentuk papul kecil berwarna merah muda, yang kadang kala mengelilingi komedo sehingga tampak hitam pada bagian tengahnya, atau membentuk pustul atau kista. Akne diklasifikasikan atas tiga bagian yaitu akne vulgaris, akne venenata (kosmetika) akne komedonal [5]. Jenis-jenis jerawat berdasarkan tingkat berat ringannya penyakit terbagi menjadi 3 skala, yaitu: Ringan (Whitehead dan Blackhead), Sedang (Papula dan Pustula) dan Berat (Nodula dan Konglobata/Kista) [6].

\section{B. Sistem Pakar}

Sistem pakar adalah program pemberi advis/nasehat yang terkomputerisasi yang ditujukan untuk meniru proses reasoning (pertimbangan) dan pengetahuan dari pakar dalam menyelesaikan permasalahan masalah yang spesifik. Bidang ini digunakan lebih banyak daripada penggunaan bidangbidang Kecerdasan Buatan lainnya [12]. Sanjaya dan Divayana menjelaskan bahwa "In Expert sistem is an artificial intelligence sistem that combines the basics of knowledge and inferential motor in such a way that it can adopt the ability of an expert into the computer, so that the computer can solve problems such as those often done by experts. In Expert sistem is a kind of contemporary software that makes computer more useful than before" yang dapat diartikan bahwa sistem pakar adalah sistem kecerdasan buatan yang menggabungkan dasar-dasar pengetahuan dan motor inferensial sedemikian rupa sehingga dapat mengadopsi kemampuan seorang ahli kedalam komputer sehingga nantinya komputer dapat memecahkan masalah seperti yang dilakukan oleh seorang ahli [7]. Divayana juga menyatakan bahwa sistem pakar merupakan suatu sistem kecerdasan buatan yang mengkombinasikan basis pengetahuan dengan mesin inferensi sehingga dapat mengadopsi kemampuan para ahli (pakar) ke dalam suatu komputer, sehingga komputer dapat menyelesaikan permasalahan-permasalahan seperti yang sering dilakukan oleh para ahli [8].

Sistem pakar merupakan sistem yang mengadopsi kemampuan para pakar, sehingga sistem dapat memecahkan permasalahan pada domain tertentu seperti yang biasanya dilakukan oleh para pakar [9]. Sistem pakar adalah sistem kecerdasan buatan yang menggabungkan basis pengetahuan dengan mesin inferensi sehingga bisa mengadopsi kemampuan para ahli ke dalam komputer, sehingga komputer bisa memecahkan masalah seperti yang sering dilakukan oleh para ahli [10].

Sistem pakar adalah suatu sistem yang mengkombinasikan basis pengetahuan dan mesin inferensi sehingga dapat mengadopsi kemampuan para ahli ke dalam suatu komputer, sehingga komputer tersebut dapat memecahkan masalah layaknya seorang pakar [11].

Dari beberapa definisi tersebut, maka dapat diambil suatu kesimpulan umum bahwa sistem pakar merupakan suatu sistem yang berusaha mengadopsi kemampuan pakar ke dalam suatu komputer sehingga kamputer seolah-olah mampu bekerja seperti layaknya seorang pakar dalam memecahkan suatu permasalahan dalam domain tertentu berdasarkan basis pengetahuan dan motor inferensi.

Tujuan dari sistem pakar bukanlah menggantikan para pakar, tetapi hanya untuk membuat pengetahuan dan pengalaman para pakar itu tersimpan dan tersedia lebih luas dan leluasa [8].

\section{Certainty Factor}

Faktor kepastian (certainty factor) menyatakan kepercayaan dalam sebuah kejadian (atau fakta atau hipotesis) berdasarkan bukti atau penilaian pakar (Turban, 2005) [9]. Certainty factor menggunakan suatu nilai untuk mengasumsikan derajat keyakinan seorang pakar terhadap suatu data. Certainty factor memperkenalkan konsep keyakinan dan ketidakyakinan yang kemudian diformulasikan ke dalam rumusan dasar sebagai berikut:

$$
C F(H, E)=M B(H, E)-M D(H, E)
$$

Dimana MB merupakan ukuran kepercayaan (measure of increased belief) dan MD merupakan ukuran 
ketidakpercayaan (measure of increased disbelief). Ada dua cara dalam mendapatkan tingkat keyakinan (CF) dari sebuah rule, yaitu : Metode Net Belief yang diusulkan oleh E.H Shortliffe dan B.G Buchanan. Kedua adalah mewawancarai seorang pakar. Nilai CF (Rule) didapat dari interpretasi dari seorang pakar yang diubah menjadi nilai CF tertentu [10]. Berikut ini merupakan rule certainty factor disajikan pada Tabel 1. Certainty Term User

\begin{tabular}{|l|l|l|}
\hline No & \multicolumn{1}{|c|}{ Certainty Term } & MD/MB \\
\hline 1. & Tidak Tahu / Tidak Ada & 0.2 \\
\hline 2. & Mungkin & 0.4 \\
\hline 3. & Kemungkinan Besar & 0.6 \\
\hline 4. & Hampir Pasti & 0.8 \\
\hline 5. & Pasti & 1 \\
\hline
\end{tabular}

\section{METODE PENELITIAN}

A. Fase Perancangan Syarat-

Penyakit jerawat (acne vulgaris) yang akan dibahas pada penelitian ini ada 6 (enam) jenis penyakit dan 3 (tiga) tingkat keparahan penyakit jerawat. Tabel 2 menunjukan basis pengetahuan dari seorang pakar.

Tabel 2 Basis Pengetahuan Jerawat

\begin{tabular}{|c|c|c|c|c|c|c|}
\hline \multirow{2}{*}{$\begin{array}{l}\text { Kode } \\
\text { Gejala }\end{array}$} & \multicolumn{6}{|c|}{ Kode Penyakit Jerawat } \\
\hline & $\mathrm{P} 1$ & P2 & P3 & P4 & P5 & P6 \\
\hline G1 & $\sqrt{ }$ & & & & & \\
\hline G2 & & $\sqrt{ }$ & & & & \\
\hline G3 & & & $\sqrt{ }$ & $\sqrt{ }$ & $\sqrt{ }$ & $\sqrt{ }$ \\
\hline $\mathrm{G} 4$ & $\sqrt{ }$ & $\sqrt{ }$ & $\sqrt{ }$ & $\sqrt{ }$ & $\sqrt{ }$ & $\sqrt{ }$ \\
\hline G5 & $\sqrt{ }$ & $\sqrt{ }$ & $\sqrt{ }$ & $\sqrt{ }$ & $\sqrt{ }$ & $\sqrt{ }$ \\
\hline $\mathrm{G} 6$ & $\sqrt{ }$ & $\sqrt{ }$ & $\sqrt{ }$ & $\sqrt{ }$ & $\sqrt{ }$ & $\sqrt{ }$ \\
\hline G7 & $\sqrt{ }$ & $\sqrt{ }$ & $\sqrt{ }$ & $\sqrt{ }$ & $\sqrt{ }$ & $\sqrt{ }$ \\
\hline G8 & & & & $\sqrt{ }$ & $\sqrt{ }$ & $\sqrt{ }$ \\
\hline G9 & $\sqrt{ }$ & $\sqrt{ }$ & $\sqrt{ }$ & & & \\
\hline G10 & $\sqrt{ }$ & $\sqrt{ }$ & $\sqrt{ }$ & $\sqrt{ }$ & & \\
\hline G11 & & & & & $\sqrt{ }$ & $\sqrt{ }$ \\
\hline G12 & . & . & $\sqrt{ }$ & $\sqrt{ }$ & $\sqrt{ }$ & \\
\hline G13 & $\sqrt{ }$ & $\sqrt{ }$ & & & & $\sqrt{ }$ \\
\hline G14 & $\sqrt{ }$ & $\sqrt{ }$ & & & & \\
\hline G15 & & & & $\sqrt{ }$ & $\sqrt{ }$ & $\sqrt{ }$ \\
\hline G16 & & & & $\sqrt{ }$ & $\sqrt{ }$ & $\sqrt{ }$ \\
\hline G17 & $\sqrt{ }$ & $\sqrt{ }$ & $\sqrt{ }$ & & & \\
\hline G18 & & & & $\sqrt{ }$ & $\sqrt{ }$ & $\sqrt{ }$ \\
\hline G19 & & & & $\sqrt{ }$ & & $\sqrt{ }$ \\
\hline G20 & & & $\sqrt{ }$ & & $\sqrt{ }$ & \\
\hline G21 & & & & & & $\sqrt{ }$ \\
\hline G22 & $\sqrt{ }$ & $\sqrt{ }$ & $\sqrt{ }$ & $\sqrt{ }$ & & \\
\hline
\end{tabular}

\begin{tabular}{|c|c|c|c|c|c|c|}
\hline Kode & \multicolumn{5}{|c|}{ Kode Penyakit Jerawat } \\
\cline { 2 - 7 } Gejala & P1 & P2 & P3 & P4 & P5 & P6 \\
\hline G23 & & & & & $\sqrt{ }$ & $\sqrt{ }$ \\
\hline
\end{tabular}

Keterangan :

P1 : jenis jerawat Whitehead

P2 : jenis jerawat Blackhead

P3 : jenis jerawat Papula

P4 : jenis jerawat Pustula

P5 : jenis jerawat Nodula

P6 : jenis jerawat Konglobata/Kista

Analisis rule penyakit pada sistem pakar ini berjumlah 161 rule dimana tiap rule memiliki nilai keyakinan (CF) pakar yang berbeda-beda. Proses konsultasi penyakit jerawat diawali dengan pemberian pilihan jawab yang memiliki tingkat kepastian tertentu oleh user. Nilai kepastian tersebut diterjemahkan dengan menggunakan tabel interpretasi 'term' yang kemudian dihitung dalam sistem. Tabel 3. menunjukan nilai interpretasi dari nilai kepastian (CF) dari user. Tabel 4. menunjukan inisiasi lesi yang timbul di area wajah berdasarkan certainty term.

Tabel 3. Nilai Interpretasi dari nilai kepastian (CF) User

\begin{tabular}{|l|c|}
\hline \multicolumn{1}{|c|}{ Certainty Term } & Nilai CF User \\
\hline Tidak ada & 0 \\
\hline Kadang-kadang & 0.25 \\
\hline Cukup sering & 0.5 \\
\hline Sering & 0.75 \\
\hline Sangat sering & 1.0 \\
\hline
\end{tabular}

Tabel 4. Inisiasi lesi pada area wajah

\begin{tabular}{|l|c|}
\hline \multicolumn{1}{|c|}{ Certainty Term } & Inisiasi Lesi \\
\hline Tidak ada & 0 lesi \\
\hline Kadang-kadang & $1-3$ lesi \\
\hline Cukup sering & $4-5$ lesi \\
\hline Sering & $6-10$ lesi \\
\hline Sangat sering & $<10$ lesi \\
\hline
\end{tabular}

Sistem akan menampilkan seluruh pertanyaan. Kemudian user akan memilih gejala yang dialami berikut dengan nilai keyakinannya (CF). Nilai 0 menunjukan bahwa user tidak mengalami gejala seperti yang ditanyakan oleh user, maka gejala tersebut dapat diabaikan dan tidak terhitung kedalam sistem. Semakin user sering mengalami gejala yang ditanyakan oleh sistem maka semakin tinggi nilai keyakinan 
yang diperoleh. Berikut langkah-langkah dalam mendiagnosa penyakit.

1. Dokter atau pakar akan memberikan rule berupa nilai CF dari gejala penyakit jerawat.

2. Kemudian sistem akan menampilkan pertanyaan masing-masing gejala dengan menerapkan metode penelusuran forward chaining.

3. Sistem akan mengeksekusi rule kemudian mengalikan rule tersebut dengan nilai CF dari user.

4. Mengombinasikan nilai CF dari masingmasing kaidah dengan rumus CF Gabungan.

5. Setelah mendapatkan persentase dari satu penyakit dan terdapat rule yang memenuhi kaidah dari penyakit lainnya maka sistem kembali melakukan iterasi perhitungan untuk menghitung persentase untuk jenis penyakit lainnya.

6. Berdasarkan jenis penyakit yang diderita, dapat disimpulkan tingkat keparahan penyakit dan diderita dan sistem akan memberikan treatment kepada pasien.

\section{B. Fase Perancangan Sistem}

Proses perancangan sistem difokuskan pada tiga atribut, yaitu perancangan alur data, perancangan database, representasi antar muka. Gambaran secara umum tentang cara kerja sistem ini dapat dijelaskan melalui diagram konteks. Di dalam diagram ini akan menggambarkan hubungan antara masukan dan keluaran, hubungan sistem dengan entitas luar. Fasilitas luar yang berhubungan dengan sistem ini adalah Admin dan Pengguna (user regular). Gambar 1. menunjukkan diagram level 1 dari sistem pakar diagnosis penyakit jerawat di wajah dengan metode certainty factor.

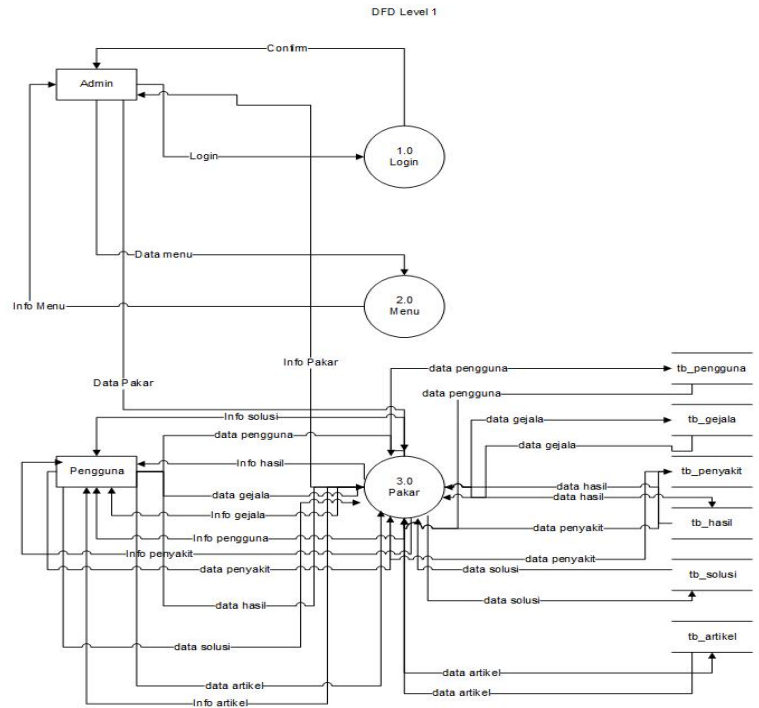

Gambar 1 Diagram Level 1 Sistem Pakar Diagnosis Jerawat

Rancangan antar tabel disini menggambarkan hubungan antara tabeltabel yang terdapat dalam basis data Sistem pakar diagnosis penyakit jerawat. Pada tahap perancangan, terdapat 13 tabel yang mendukung dalam pembuatan sistem ini. Berikut ini adalah Gambar 2. relasi antar tabel sistem diagnosis penyakit jerawat.

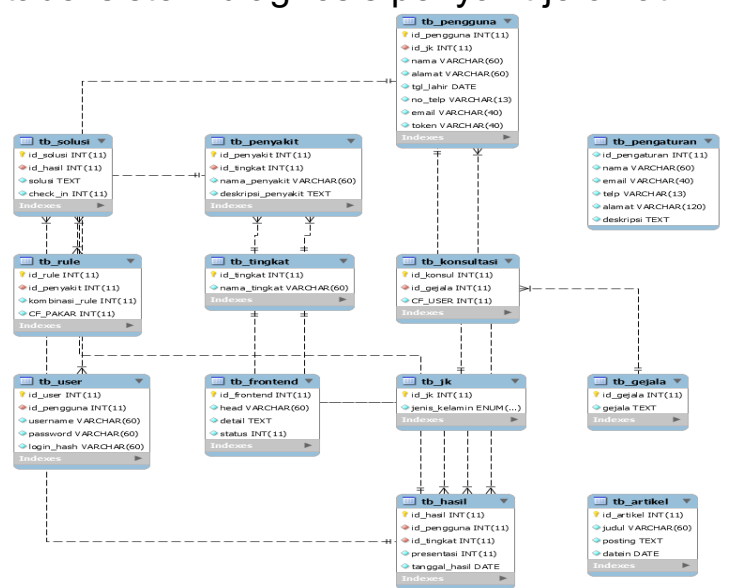

Gambar 2 Relasi Antar Tabel Sistem Pakar Diagnosis Jerawat

Representasi antarmuka atau yang sering dikenal juga dengan rancangan interface merupakan rancangan tampilan atau posisi informasi yang akan ditampilkan pada sistem sehingga membantu pengguna saat menggunakannya. Rancangan antarmuka dari Sistem Pakar Diagnosis Penyakit Jerawat di Wajah dengan Metode Certainty Factor dirancang dengan menggunakan design Flat sehingga 
membuat tampilan interface menjadi lebih dinamis dan elegan.

\section{IMPLEMENTASI DAN PENGUJIAN}

A. Implementasi Antarmuka Perangkat Lunak

Implementasi antarmuka dari sistem pakar diagnosis penyakit jerawat menggunakan design Flat sehingga membuat tampilan interface menjadi lebih dinamis dan elegan. Tampilan dalam sistem pakar ini terdiri dari 2 web utama yaitu web admin dan web user. Berikut pemaparan lebih detail mengenai implementasi antarmuka perangkat lunak sistem pakar diagnosis penyakit jerawat.

\section{Implementasi Antarmuka Web Admin}

a. Halaman Login

Sebelum user masuk kedalam sistem admin, user terlebih dahulu memasukan username, password dan kode captcha yang benar, kemudian sistem akan melakukan verifikasi data. Jika benar, maka user akan masuk ke halaman admin. Jika salah, sistem akan memberikan sebuah peringatan. Implementasi halaman login dapat dilihat pada Gambar 3.

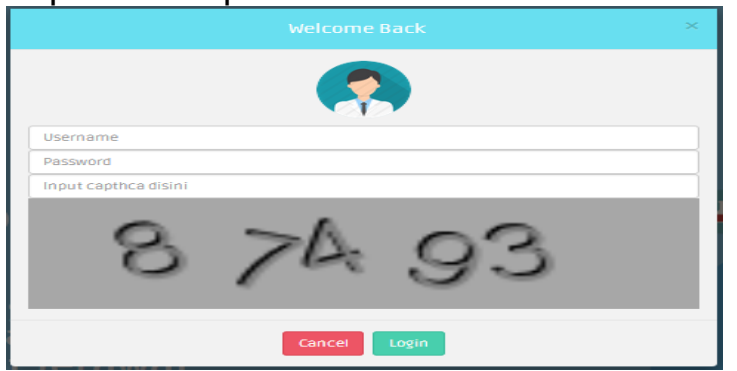

Gambar 3 Antarmuka Halaman Login

b. Halaman Utama (Dashboard)

Halaman dashboard adalah halaman utama admin yang akan dilihat. Pada halaman dashboard berisi ringkasan datadata yang sudah masuk kedalam database dan juga akan menampilkan informasi pengembang. Implementasi halaman utama (dashboard) dapat dilihat pada Gambar 4.

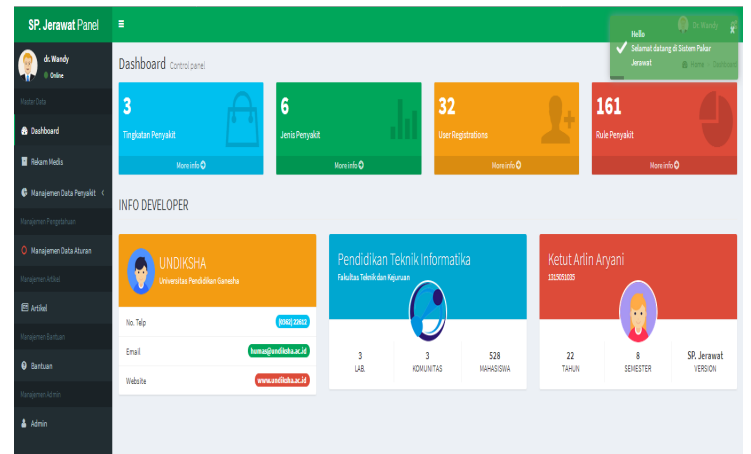

Gambar 4 Antarmuka Halaman Utama (Dashboard)

c. Halaman Rekam Medis

Halaman rekam medis menampilkan proses manipulasi data rekam medis pasien berupa detail informasi data rekam medis dan menghapus data rekam medis. Admin maupun pakar tidak diijinkan untuk melakukan perubahan data dan menambah data rekam medis pasien secara sembarangan. Implementasi halaman rekam medis dapat dilihat pada Gambar 5.

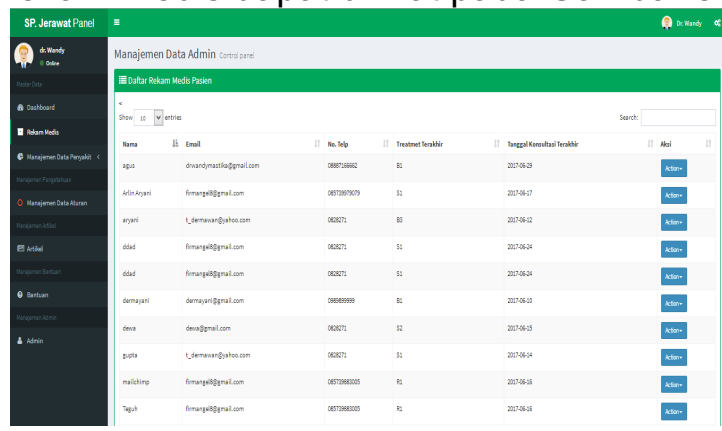

Gambar 5 Halaman Rekam Medis

\section{d. Halaman Tingkatan Penyakit}

Halaman tingkatan penyakit masuk kedalam menu manajemen data penyakit yang menampilkan proses manipulasi data tingkatan penyakit yaitu menambah, menyunting, menghapus dan melihat detail dari tingkatan penyakit. Implementasi halaman tingkatan penyakit dapat dilihat pada Gambar 6.

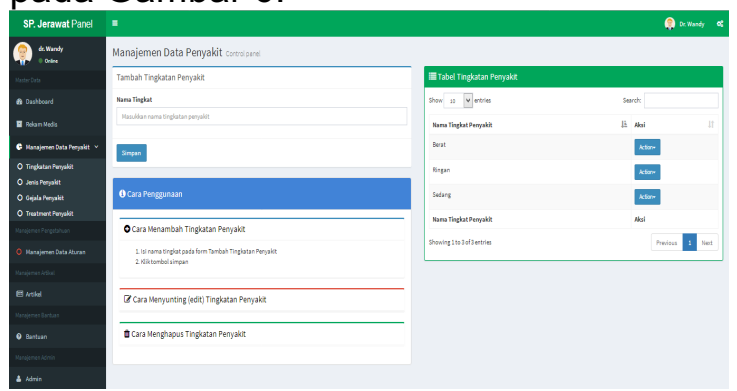

Gambar 6 Halaman Tingkatan Penyakit 
e. Halaman Jenis Penyakit

Halaman jenis penyakit masuk kedalam menu manajemen data penyakit yang menampilkan proses manipulasi data jenis penyakit yaitu menambah, menyunting, menghapus dan melihat detail dari jenis penyakit. Implementasi halaman jenis penyakit dapat dilihat pada Gambar 7 .

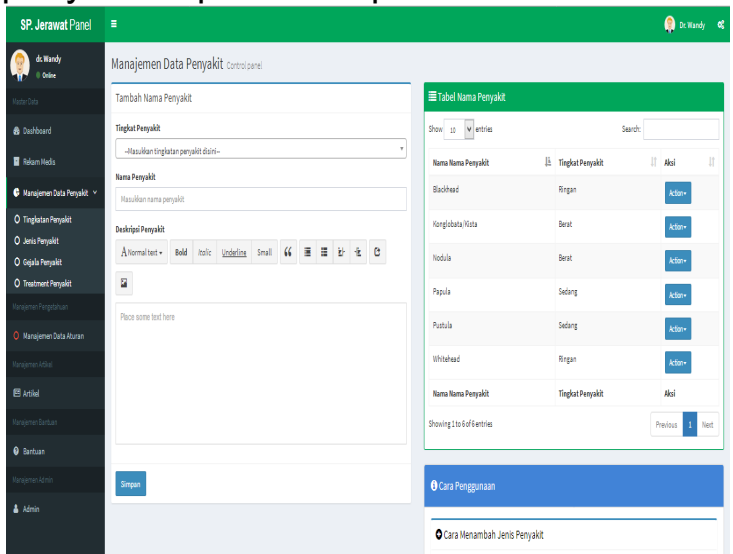

Gambar 7 Halaman Jenis Penyakit

f. Halaman Gejala Penyakit

Halaman gejala penyakit masuk kedalam menu manajemen data penyakit yang menampilkan proses manipulasi data tingkatan penyakit yaitu menambah, menyunting, menghapus dan melihat detail dari gejala penyakit. Implementasi halaman gejala penyakit dapat dilihat pada Gambar 8 .

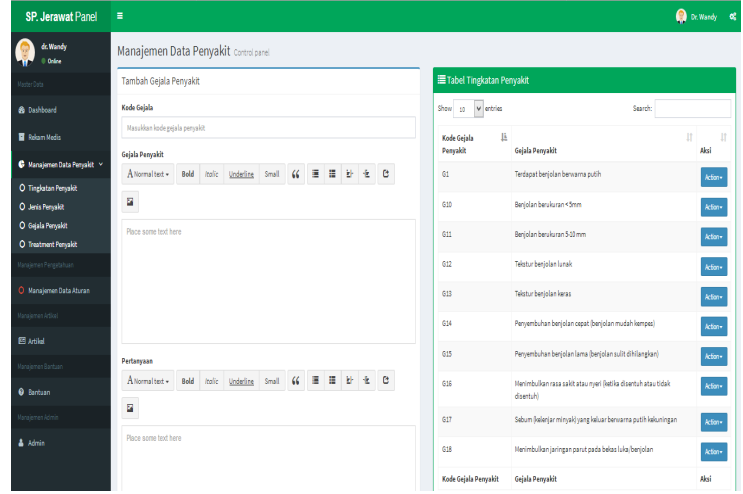

Gambar 8 Halaman Gejala Penyakit

g. Halaman Manajemen Data Aturan

Halaman manajemen data aturan menampilkan proses manipulasi data aturan I rule pada tiap jenis penyakit yaitu menambah, menyunting, menghapus dan melihat detail dari tiap aturan / rule. Implementasi halaman manajemen data aturan dapat dilihat pada Gambar 9.

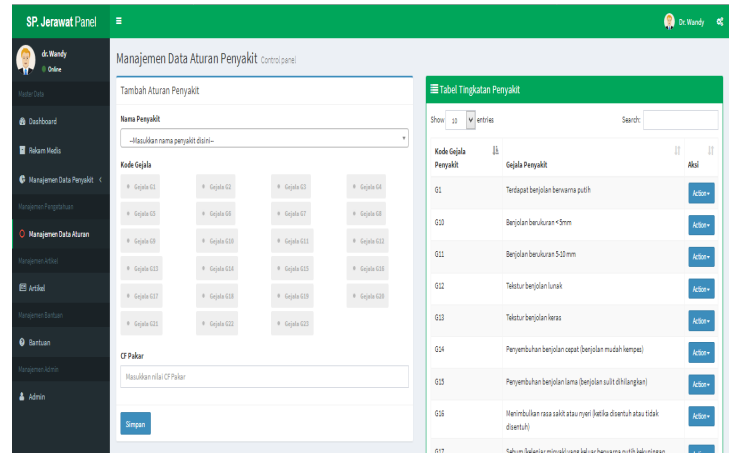

Gambar 9 Halaman Manajemen Data Aturan

h. Halaman Manajemen Artikel

Halaman manajemen

artikel menampilkan proses manipulasi data artikel yaitu menambah, menyunting, menghapus dan melihat detail dari tiap artikel baik yang bersifat draft maupun yang diposting ke halaman user. Implementasi halaman manajemen artikel dapat dilihat pada Gambar 10.

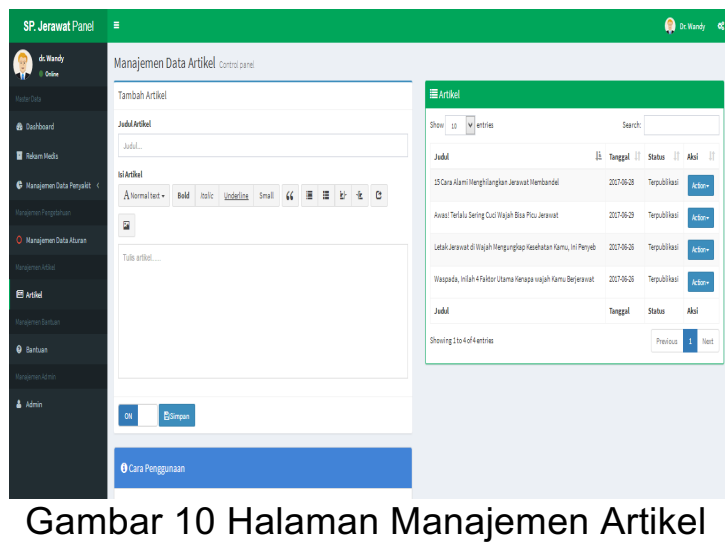

i. Halaman Manajemen Admin

Halaman manajemen

admin menampilkan proses manipulasi data admin yaitu menambah, menyunting, menghapus dan melihat username dari tiap user yang terdaftar sebagai admin/pakar. Implementasi halaman manajemen admin dapat dilihat pada Gambar 11.

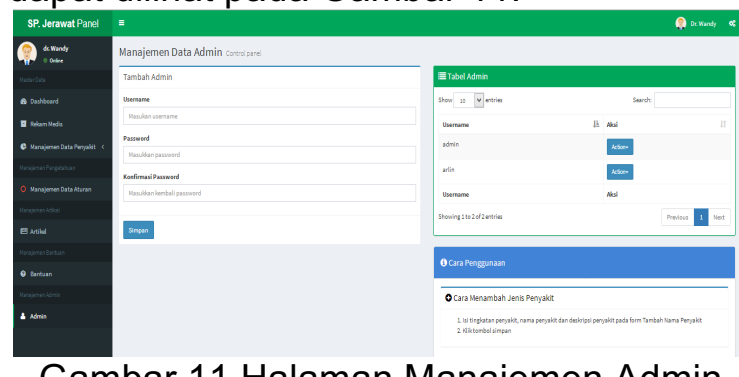

Gambar 11 Halaman Manajemen Admin 
j. Halaman Pengaturan

Halaman pengaturan menampilkan proses manipulasi data pengaturan meliputi profil pakar yaitu menambah, menyunting, menghapus dan melihat detail dari profil pakar. Implementasi halaman pengaturan dapat dilihat pada pada Gambar 12.

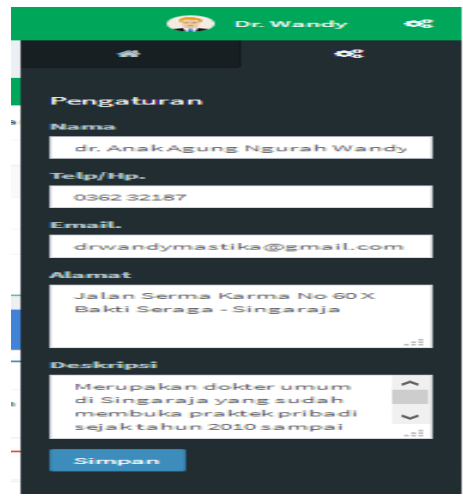

Gambar 12 Halaman Pengaturan

2. Implementasi Antarmuka Web User

a. Halaman Login Pengguna

Halaman login pengguna ditujukan bagi tiap pengguna yang sudah melakukan proses konsultasi sebelumnya dan memasukan data diri dengan benar. Pengguna akan mendapatkan kode token yang secara otomatis akan dikirim oleh sistem via email yang terdaftar. Kode token inilah yang akan menjadi username sekaligus password untuk pengguna agar dapat melakukan konsultasi lanjutan dan melihat rekam medis pasien. Implementasi halaman login member dapat dilihat pada Gambar 13.

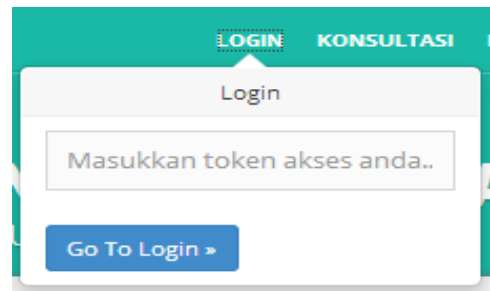

Gambar 13 Halaman Login Pengguna

b. Halaman Konsultasi

Halaman konsultasi merupakan halaman utama yang akan muncul di halaman pengguna. Pada halaman konsultasi akan ditampilkan form data diri pasien dan lanjut pengisian form konsultasi penyakit jerawat. Implementasi halaman konsultasi dapat dilihat pada Gambar 14.

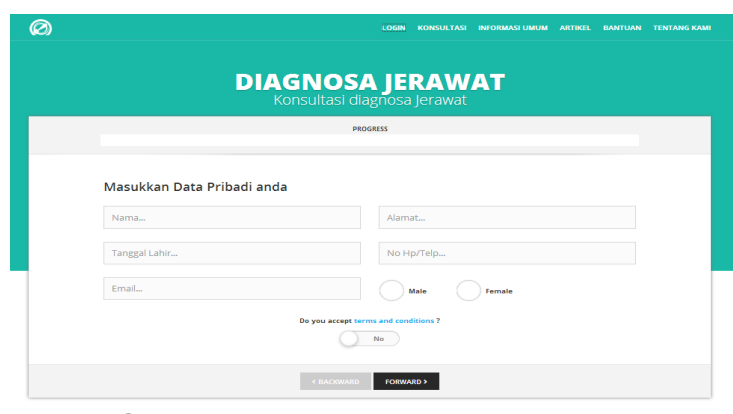

Gambar 14 Halaman Konsultasi

c. Halaman Bantuan

Halaman bantuan merupakan halaman yang menampilkan informasi terkait penggunaan sistem pakar diagnosis penyakit jerawat. Halaman bantuan ini juga berfungsi untuk menyamakan informasi terkait gejala-gejala pada penyakit jerawat yang muncul pada saat pengisian form konsultasi. Implementasi halaman bantuan dapat dilihat pada Gambar 15.

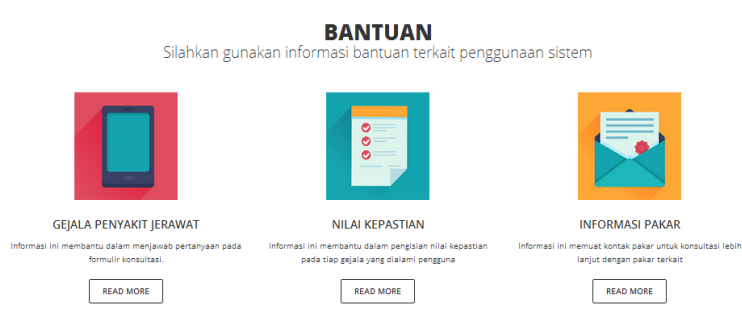

Gambar 15 Halaman Bantuan

d. Halaman Artikel

Halaman artikel merupakan halaman yang menampilkan artikel-artikel terkait dunia kedokteran khususnya untuk kecantikan kulit dan penanganan umum penyakit jerawat. Halaman artikel ini disertai dengan situs terpercaya untuk menghindari kesalahan informasi (hoax). Implementasi halaman artikel dapat dilihat pada gambar 16.

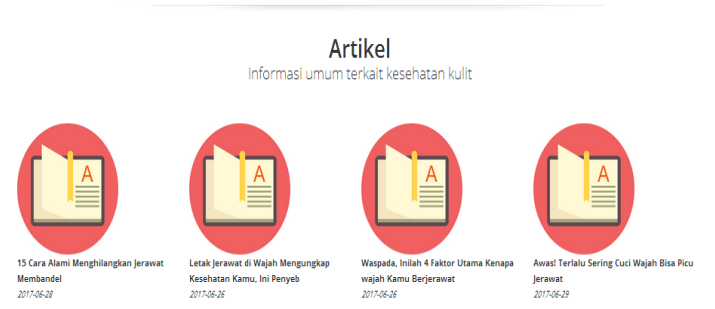

Gambar 16 Halaman Artikel 
e. Halaman Informasi Umum

Halaman informasi umum menampilkan informasi ringkas mengenai jenis-jenis penyakit jerawat di wajah. Informasi umum ini nantinya dapat menambah pengetahuan pengguna terkait jenis-jenis penyakit jerawat di wajah. Adapun implementasi halaman informasi umum dapat dilihat pada gambar 17.

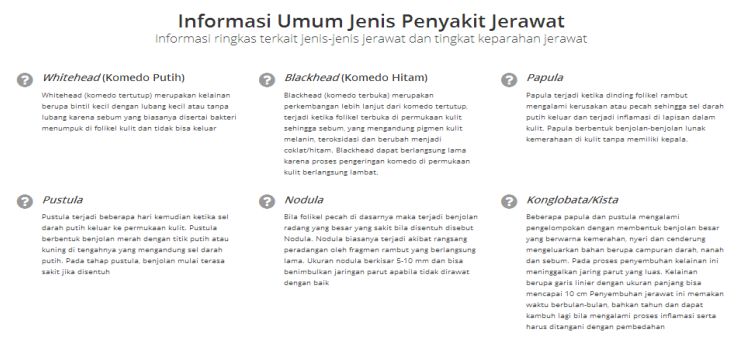

Gambar 17 Halaman Informasi Umum

f. Halaman Tentang Kami

Halaman tentang kami menampilkan nama pakar yang berkontribusi dalam pengembangan sistem pakar diagnosis penyakit jerawat dan nama pengembang sistem pakar diagnosis penyakit jerawat. Adapun implementasi halaman tentang kami dapat dilihat pada gambar 18 .

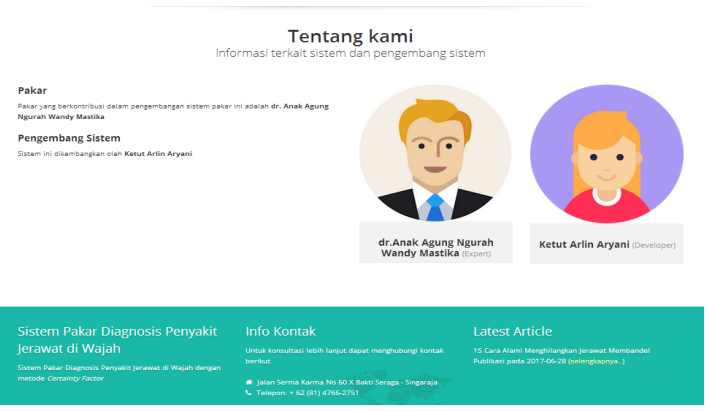

Gambar 18 Halaman Tentang Kami

g. Halaman Rekapitulasi Hasil

Perhitungan

Setelah user mengisi form konsultasi dengan benar maka sistem akan menampilkan halaman rekapitulasi hasil perhitungan dengan metode certainty factor. Pada halaman ini akan menampilkan jenis penyakit yang diderita beserta persentasenya dan tingkat keparahan penyakit. Implementasi halaman rekapitulasi hasil perhitungan dapat dilihat pada gambar 19.

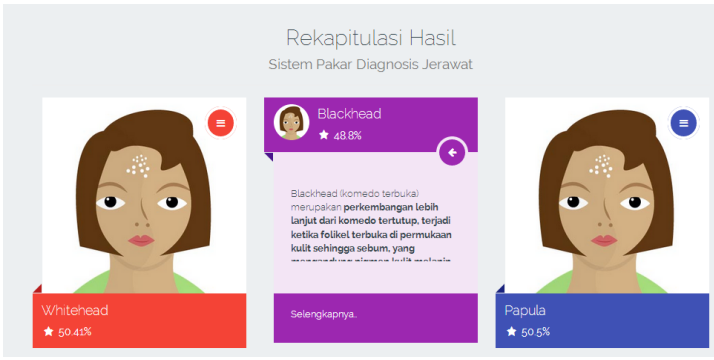

Gambar 19 Halaman Rekapitulasi Hasil

h. Halaman Rekam Medis

Halaman rekam medis pasien merupakan halaman yang menampilkan keseluruhan rekam medis pasien. Untuk mengakses halaman ini, pastikan user melakukan login member terlebih dahulu. Implementasi halaman rekam medis pasien dapat dilihat pada gambar 20 .

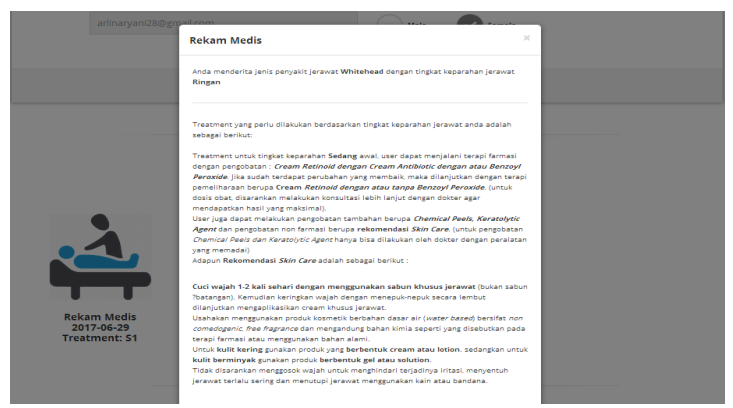

Gambar 20 Halaman Rekam Medis

B. Hasil Pengujian Perangkat Lunak

Pengujian perangkat lunak terdiri dari black box testing, white box testing dan pengujian tingkat keakuratan sistem. Pengujian black box perangkat lunak ini terdiri 1 uji kasus yang memiliki tujuan untuk menguji fungsionalitas perangkat lunak Pengujian white box, yaitu pengujian kebenaran pengimplementasian proses dan algoritma yang dibutuhkan dalam menmproses inputan user dan melakukan perhitungan dengan metode Certainty Factor. Pengujian akurasi sistem yaitu pengujian untuk menguji kebenaran output sistem dengan pengetahuan yang dimiliki oleh pakar berdasarkan inputan gejala user. Pada uji akurasi sistem, terdiri dari 20 sampel kasus dengan pasien yang sama agar dapat menghasilkan hasil treatment sesuai harapan. Tahap uji akurasi sistem dilakukan oleh pakar sesuai dengan rancangan yang telah ditetapkan oleh pengembang. Selanjutnya akan dihitung 
persentase akurasi dengan menggunakan Rumus :

Akurasi

$=\frac{\text { Jumlah rekomendasi yang sesuai }}{\text { Jumlah keseluruhan rekomendasi }} \times 100 \%$

Dari pelaksanaan masing-masing kasus uji diperoleh untuk pengujian black box yang terdiri dari pelaksanaan uji kasus yang dilakukan oleh pakar dan seorang pengguna mengenai fungsional perangkat lunak sudah sesuai.

Dari pelaksanaan uji akurasi sistem, sistem dikatakan memiliki tingkat akurasi penuh (full accuracy) apabila output yang dikeluarkan berupa jenis jerawat dan tingkat keparahan jerawat sama dengan pengetahuan pakar. Sistem dikatakan memiliki tingkat akurasi sebagian (half accuracy) apabila output yang dikeluarkan salah satunya berupa jenis jerawat atau tingkat keparahan jerawat berbeda dengan pengetahuan pakar. Dan sistem dikatakan eror (not accuracy) apabila output yang dikeluarkan sistem keseluruhan berbeda dengan pengetahuan pakar. Hasil rekapitulasi uji tingkat akurasi sistem didapat persentase tingkat keakurasian untuk full accuracy (FA) $=85 \%$, half accuracy (HA) $=15 \%$, serta not accuracy (NA) $=0 \%$.

\section{SIMPULAN}

Berdasarkan paparan hasil perancangan, analisis, implementasi, pengujian, dan evaluasi sistem yang telah dilaksanakan pada penelitian ini maka dapat diambil kesimpulan yaitu sistem pakar diagnosis penyakit jerawat ini menggunakan metode Certainty Factor (CF) untuk mendapatkan hasil diagnosis yang sesuai dengan pengetahuan yang dihimpun dari seorang pakar yaitu dr. Anak Agung Ngurah Wandy Mastika. Sistem pakar ini memiliki 23 gejala dan mampu mendiagnosis 6 jenis penyakit jerawat di wajah serta 3 tingkat keparahan jerawat. Pemberian solusi dan treatment berdasarkan tingkat keparahan jerawat yang dimiliki oleh pengguna secara bertahap (level 1-level 3 pada masingmasing tingkat keparahan). Pengujian Sistem Diagnosis Penyakit Jerawat di Wajah dengan Metode Cetainty Factor dilakukan dengan beberapa cara dan mendapatkan hasil sebagai berikut. Pertama, hasil pengujian blackbox (pengujian fungsionalitas) diperoleh bahwa proses yang dijalankan oleh pengembang (dari sisi halaman admin dan halaman pengguna), pakar (dari sisi halaman admin) dan seorang pengguna (dari sisi halaman pengguna) telah mampu berjalan dengan baik. Kedua, berdasarkan hasil pengujian whitebox (pengujian prosedural) yang dilakukan oleh pengembang diperoleh bahwa pengimplementasian algoritma telah berhasil dilakukan dengan baik. Pada pengujian ketiga yaitu uji akurasi sistem yang dilakukan oleh pakar mendapatkan hasil akurasi penuh sebesar $85 \%$, akurasi sebagian sebesar $15 \%$ dan eror sebesar $0 \%$. Berdasarkan hasil uji akurasi, maka sistem memiliki tingkat pencapaian untuk akurasi penuh sebesar $85 \%$ dan akurasi sebagian sebesar $15 \%$ sehingga disimpulkan bahwa sistem berada pada kualifikasi baik.

Berdasarkan kesimpulan diatas, dapat disarankan kepada pembaca bahwa dalam pengembangan selanjutnya, diharapkan menggunakan dokter spesialis kulit dalam mengakuisisi pengetahuan. Yang kedua, pemberian gejala unik pada tiap jenis penyakit lebih dipertegas dan diperjelas untuk menghindari adanya kesalahan diagnosis antara sistem dan pakar. Ketiga, dalam memunculkan pertanyaan disarankan untuk menyertai dengan gambar pendukung dan keempat agar data rekam medis pasien dapat dikirim via email masing-masing pengguna.

\section{REFERENSI}

[1] Soetjiningsih. (2002). Dampak Psikologis Jerawat pada Remaja. Retrieved from http://digilib.unimus.ac.id/download.php ?id=724.

[2] Sengkey. (2008). Chapter II Acne Vulgaris. Retrieved from repository.usu.ac.id/bitstream/.../4/Chap ter\%20II.pdf

[3] Wasitaatmaja. IImu Penyakit Kulit dan Kelamin. Jakarta: Universitas Indonesia. 2007.

[4] James, W. C. ACNE. London: Martin Dunitz. 1989. 
[5] Plewig, G., \& Kligman, A. Acne Morphogenesis and Treatment. New York: Surya Dermanto Medica Laboratories. 1975.

[6] Wasitaatmaja. Penuntun IImu Kosmetik Medik. Jakarta: Universitas Indonesia. 1997.

[7] Sanjaya, D. B., \& Divayana, D.G.H. An Expert Sistem-Based Evaluation of Civics Education as a Means of Character Education Based on Local Culture in the Universitas in Buleleng. International Journal of Advanced Research in Artificial Intellegence (IJARAI), 2015; 4(12): 17-21.

[8] Divayana, D.G.H. Evaluasi Program Perpustakaan Digital Berbasis Sistem Pakar Pada Universitas Teknologi Indonesia. Jakarta: Universitas Negeri Jakarta. 2016.

[9] Sugiharni, G.A.D., \& Divayana, D.G.H. Pemanfaatan Metode Forward Chaining Dalam Pengembangan Sistem Pakar
Pendiagnosa Kerusakan Televisi Berwarna. Jurnal Nasional Pendidikan Teknik Informatika (JANAPATI), 2017; 6(1): 20-29.

[10] Divayana, D.G.H. Development of Duck Diseases Expert System with Applying Alliance Method at Bali Provincial Livestock Office. International Journal of Advanced Computer Science and Applications, 2014; 5(8): 48-54.

[11] Divayana, D.G.H., \& Sugiharni, G.A.D. Sistem Pakar \& Sistem Pendukung Keputusan (Buku Ajar Pendidikan Teknik Informatika). Singaraja: Undiksha Press. 2016.

[12] Aryawan, I. K., Sunarya, I. M., \& Darmawiguna, I. G. M. Aplikasi Sistem Pakar Diagnosa Kerusakan pada Sepeda Motor 4 Tak Menggunakan Metode Certainty Factor Berbasis Android. Artikel Mahasiswa Pendidikan Teknik Informatika, 2013; 2(6): 903910. 